\title{
Aprendizagem da Língua Portuguesa com Dispositivos Móveis: Um Mapeamento Sistemático da Literatura
}

\author{
Wagner Gaspar ${ }^{1}$, Elaine H. T. Oliveira ${ }^{1}$, Kelson. M. T. Oliveira ${ }^{2}$ \\ ${ }^{1}$ Instituto de Computação - Universidade Federal do Amazonas (UFAM) \\ CEP 69.077 - 000 - Manaus - AM - Brasil \\ ${ }^{2}$ Departamento de Química - Instituto de Ciências Exatas - Universidade Federal do \\ Amazonas (UFAM) - CEP 69.077 - 000 - Manaus - AM - Brasil \\ $\{$ wg, elaine\}@icomp.ufam.edu.br, kelsonmota@ufam.edu.br
}

\begin{abstract}
With the advance, popularization and mainly due to the great range of features that are added to them, the mobile devices have become more attractive for the pedagogical practices, such as teaching Portuguese Language (PL). This study aims to analyze scientific publications in order to identify mobile learning (m-learning) applications to PL, using a Systematic Literature Mapping (SLM) to provide a wide view of the mentioned area. Results have shown that the research on m-learning and PL in Brazil are still recent, but have also shown an increase of publications in the last few years.
\end{abstract}

Resumo. Com o avanço, a popularização e principalmente devido à gama de recursos que agregam, os dispositivos móveis têm se tornado cada vez mais atrativos para as práticas pedagógicas, como, por exemplo, no ensino da Lingua Portuguesa (LP). Este estudo tem por objetivo analisar publicações científicas com o propósito de identificar aplicações mobile learning (mlearning) para a LP, utilizando um Mapeamento Sistemático da Literatura (MSL), a fim de obter uma visão geral e ampla da área de pesquisa. Os resultados mostram que as pesquisas em m-learning e LP ainda são recentes, porém têm mostrado aumento de publicações nos últimos anos.

\section{Introdução}

Com a evolução e a popularização das Tecnologias Digitais da Informação e Comunicação (TDICs), as práticas de comunicação e as relações entre os atores têm sido alteradas [Lopes 2014]. Os métodos de ensino estão incorporando as tecnologias e evoluindo, mostrando a necessidade de estudos sobre novas formas de ensino e aprendizagem [Marques e Silva 2012], tendo em vista que o processo de aprendizagem não está restrito à sala de aula e à figura do professor, mas está presente em todos os momentos em que há uma troca de experiências [Alves et al. 2012].

Neste contexto, tem-se o surgimento de aplicações m-learning que auxiliam no processo de ensino-aprendizagem para alunos nas mais diversas áreas, sendo algumas delas: aprendizagem colaborativa [Luz e Fonseca 2013], prática e aprendizagem do português através da escrita Braille [Silva et al. 2014], ensino e aprendizagem de matemática [Sena et al. 2014], dentre outros. Começaram a surgir também aplicativos para ensino e aprendizagem da Língua Portuguesa, em especial, dedicados às alterações promovidas pelo novo acordo ortográfico [Marques e Silva 2012; Paschoal et al. 2014]. 
No entanto, a aprendizagem da ortografia vai muito além da mera memorização de regras, possuindo diversos aspectos que devem ser levados em conta, como fonológicos, morfológicos, sintáticos, semânticos, e ainda as ortografias regulares, com escrita baseadas em normas ortográficas, e irregulares, que dependem de memorização para escrita correta [Meireles e Correa 2005 e 2006; Nobili e Barrera 2009].

O sistema de escrita alfabético não representa o significado das palavras, mas sua sequência fonológica [Nobili e Barrera 2009]. Baseado na correspondência entre grafemas e fonemas, a criança atribui a cada fonema um grafema correspondente, porém, a descoberta dessa natureza alfabética da linguagem não implica necessariamente no domínio das regras ortográficas [Nobili e Barrera 2009]. A aprendizagem da leitura e da escrita envolve os processos de alfabetização e de letramento, diretamente ligados à capacidade de compreensão e produção de texto, processos estes fundamentais no ensino fundamental, no entanto, no que se refere ao ensino publico, está longe do almejado [Nobili e Barrera 2009]. Assim, uma investigação com o objetivo de averiguar o que vem sendo desenvolvido para tentar amenizar esta carência no domínio da LP, mostra-se efetivamente necessária.

Este trabalho apresenta um mapeamento sistemático da literatura, com o propósito de analisar relatos de experiências e publicações científicas, a fim de identificar aplicações m-learning para a LP. Além desta seção de introdução, o artigo está estruturado da seguinte forma: a seção 2 apresenta trabalhos de MSL, a seção 3 descreve a metodologia empregada, a seção 4 discute a análise dos resultados e a seção 5 apresenta as considerações finais e os trabalhos futuros.

\section{Mapeamento Sistemático da Literatura}

Ao iniciar a avaliação de um domínio, caso se perceba a existência de poucas evidências, ou que o tema é muito amplo, um MSL, inicialmente muito utilizado em pesquisas médicas [Kitchenham et al. 2011; Petersen et al. 2008], pode ser mais apropriado que uma Revisão Sistemática da Literatura (RSL), permitindo traçar evidências com elevado nível de granularidade [Kitchenham e Charters 2007].

Um MSL é realizado com a finalidade de fornecer uma visão geral da área de investigação, determinar se existem evidências e fornecer uma indicação desta quantidade. Seus resultados podem indicar áreas em que seja mais adequado a realização de uma RSL e áreas em que seja mais apropriada a realização de estudos preliminares [Kitchenham e Charters 2007]. Usa a mesma metodologia da RSL, porém visa identificar e classificar toda investigação relacionada a um tema amplo, respondendo questões de mais alto nível [Kitchenham et al. 2011; Petersen et al. 2008].

As principais diferenças de uma RSL são: questões mais amplas, podendo ter várias questões de pesquisa; normalmente devolvem um grande número de publicações; o processo de extração é mais amplo, devendo fornecer informações suficientes para classificar e categorizar a publicação; e a etapa de análise se constitui de um resumo dos dados a fim de responder as questões de pesquisa [Kitchenham et al. 2011].

No Brasil, muitos pesquisadores têm proposto MSLs a fim de compreender o estado atual da arte em diversas áreas. Em Borges et al. (2013) um mapeamento acerca da aplicação da gamificação à educação é proposto. Em Magalhães et al. (2013), os autores propõem uma caracterização da pesquisa em educação no Brasil, Ramires et al. (2013), apresentam um MSL onde foi conduzida uma catalogação e divulgação dos 
recursos que auxiliam as pessoas com deficiência no processo de ensino/aprendizagem e Alves e Aguiar (2014), apresentam um MSL sobre a acessibilidade e tecnologia assistiva no ambiente educacional. Ressaltamos que esta não é uma busca exaustiva da literatura, mas apresenta apenas alguns trabalhos recentes de destaque que ajudam na compreensão a cerca de um MSL.

\section{Metodologia}

Este MSL foi elaborado em quatro etapas principais, baseado no processo aplicado para engenharia de software em Petersen et al. (2008).

\subsection{Definição do Escopo do Mapeamento}

Nesta etapa, foi elaborado o protocolo do MSL, bem como: a definição da pesquisa e como ela foi conduzida, as fontes, as strings de busca, os critérios de aceitação, os objetivos e as questões de pesquisa apresentadas na Tabela 1.

Tabela 1 - Questões de Pesquisa

\begin{tabular}{|c|l|}
\hline Identificador & \multicolumn{1}{c|}{ Questões de Pesquisa } \\
\hline QP1 & $\begin{array}{l}\text { Quais aplicações m-learning baseadas no ensino da LP auxiliam a aprendizagem dos alunos em } \\
\text { diferentes níveis de ensino? }\end{array}$ \\
\hline QP2 & Quais recursos são implementados nas aplicações m-learning identificadas? \\
\hline QP3 & Quais conteúdos da LP são abordados pelas aplicações? \\
\hline
\end{tabular}

Uma pesquisa exploratória foi conduzida, e uma lista de controle foi elaborada com cinco publicações encontradas. As fontes dessas publicações foram incluídas no conjunto de fontes que iriam compor o MSL. Para cada publicação da lista de controle, suas referências foram avaliadas em busca de novas fontes em LP, para cada fonte ainda não avaliada, uma breve análise foi feita de suas publicações, para então decidir se a mesma seria ou não incluída no grupo final de fontes.

Por fim, as seguintes fontes foram definidas para obtenção das publicações: Congresso Brasileiro de Informática na Educação (CBIE) com o Simpósio Brasileiro de Informática na Educação (SBIE) e o Workshop de Informática na Escola (WIE), o Congresso Internacional da Associação Brasileira de Educação a Distância (CIAED), a Revista Philologus do Circulo Fluminense de Estudos Filológicos e Linguísticos, a Revista de Educação a Distância EmRede e a Revista da Unidade de Investigação do Instituto Politécnico de Santarém (UIIPS). Foram definidos os critérios de exclusão apresentados na Tabela 2, com a finalidade de garantir a delimitação do escopo em língua portuguesa e dispositivos móveis.

Tabela 2: Critérios de Exclusão

\begin{tabular}{|c|l|}
\hline Critério & \multicolumn{1}{|c|}{ Definição dos Critérios de Exclusão } \\
\hline CE1 & $\begin{array}{l}\text { Não serão selecionadas publicações que não tenham o texto completo do trabalho disponível através da } \\
\text { Internet e que também não se consiga através de contato com os autores; }\end{array}$ \\
\hline CE2 & $\begin{array}{l}\text { Não serão selecionadas publicações que nitidamente trate de outros assuntos não pertinentes ao objetivo } \\
\text { deste mapeamento sistemático; }\end{array}$ \\
\hline CE3 & $\begin{array}{l}\text { Não serão selecionadas publicações em que as palavras-chave da busca não apareçam no título, resumo } \\
\text { e/ou lista de palavras-chave da publicação (excluem-se os seguintes campos: as seções de } \\
\text { agradecimentos, biografia dos autores, referências bibliográficas e anexos). }\end{array}$ \\
\hline CE4 & $\begin{array}{l}\text { Não serão selecionadas publicações que descrevam e/ou apresentem "keynote speech", tutoriais, cursos, } \\
\text { editoriais, workshops e similares. }\end{array}$ \\
\hline
\end{tabular}


Baseado nestes, foram automaticamente excluídos os trabalhos que atendessem a pelo menos um dos critérios. Foram definidos como critérios de inclusão os apresentados na Tabela 3, visando identificar o foco de cada publicação selecionada.

Tabela 3: Critérios de Inclusão

\begin{tabular}{|c|l|}
\hline Critério & \multicolumn{1}{c|}{ Definição dos Critérios de Inclusão } \\
\hline $\mathrm{Cl} 1$ & Publicações que citem aplicações m-learning referentes à aprendizagem de língua portuguesa. \\
\hline $\mathrm{Cl} 2$ & Publicações que apresentem aplicações m-learning referentes à aprendizagem de língua portuguesa. \\
\hline $\mathrm{Cl} 3$ & $\begin{array}{l}\text { Publicações que apresentem relatos de experiências desde que estejam relacionados a aplicações m- } \\
\text { learning referentes à aprendizagem de língua portuguesa. }\end{array}$ \\
\hline
\end{tabular}

Todo trabalho selecionado cumpriu obrigatoriamente ao menos um dos critérios de inclusão. A busca foi realizada de forma manual com a utilização de strings de busca apresentadas na Tabela 4. Por se tratar de um tópico escasso, publicações em Inglês e Espanhol não foram excluídas, porém, nenhuma foi aprovada nos critérios de inclusão.

Tabela 4: Strings de Busca Utilizadas

\begin{tabular}{|c|c|}
\hline Idioma & String de Busca \\
\hline Português & $\begin{array}{l}\text { ("português" OU "Português" OU "Língua Portuguesa" OU "língua portuguesa") and ("m-learning" OU } \\
\text { "M-learning" OU "Mobile learning" OU "M-Learning" OU "mobile learning".) }\end{array}$ \\
\hline Inglês & $\begin{array}{l}\text { ("Portuguese" OU "portuguese" OU "portuguese language" OU "Portuguese Language") and ("m- } \\
\text { learning" OU "M-learning" OU "Mobile learning" OU "M-Learning" OU "mobile learning".) }\end{array}$ \\
\hline Espanhol & $\begin{array}{l}\text { (“portugues" OU "Portugues" OU "lengua portugues" OU "Lengua Portugues") and ("m-learning" OU "M- } \\
\text { learning" OU "Mobile learning" OU "M-Learning" OU "mobile learning".) }\end{array}$ \\
\hline
\end{tabular}

\subsection{Busca e Classificação dos Estudos Primários}

Com o protocolo da pesquisa finalizado, deu-se início à segunda etapa, com a busca e a classificação das publicações. Foram recuperadas todas as publicações disponíveis no site oficial de cada fonte. Para o CIAED, todas as publicações a partir de 2001 foram recuperadas (1982). Para o SBIE, foram recuperadas todas as publicações a partir de 2001 (1421) e para o WIE, a partir de 2003, com exceção de 2004, que não se encontrava disponível (595). Para a revista Philologus, todas as edições foram recuperadas a partir de 1995 (1116), para a revista EmRede, a partir de 2014 (11) e para a revista da UIIPS, todas as edições a partir de 2013 (342), totalizando 5467 publicações.

$\mathrm{Na}$ primeira análise, foram examinados o título, o resumo e as palavras-chave, em busca das strings definidas na Tabela 4. Uma vez não encontradas, a publicação foi classificada em um dos critérios de exclusão apresentados na Tabela 2. Passaram para a segunda análise um total de nove publicações, sendo classificadas em ao menos um dos critérios de inclusão apresentados na Tabela 3.

\subsection{Extração dos Dados}

Cada publicação selecionada foi lida e teve seus dados extraídos a fim de responder as questões de pesquisa. Para auxiliar no processo, uma planilha do LibreOffice Calc foi utilizada. Os dados de interesse foram: título, autores, palavras-chave, ano, fonte, resumo, conteúdos abordados da LP, recursos tecnológicos utilizados, e, se houve alguma aplicação prática, como esta foi realizada e suas conclusões. 


\subsection{Análise e Síntese}

A partir dos dados extraídos na fase anterior, procedeu-se com a análise e a geração de gráficos e tabelas, a fim de sintetizar as informações obtidas. Todos os dados, critérios utilizados, buscas, fontes e toda a metodologia adotada foi documentada em um relatório final do MSL, assim como a referência para todas as publicações avaliadas.

\section{Resultados e Discussões}

Com os primeiros resultados da MSL, percebeu-se que o escopo desta pesquisa trata de um tópico desafiador e instigante, especialmente devido a escassez de dados na literatura. A Tabela 5 apresenta um quadro contendo as nove publicações selecionadas, bem como o título, os autores, a proposta, a fonte, o critério de inclusão aprovado e a entidade a qual os pesquisadores estão vinculados. Os mesmos encontram-se ordenados unicamente por ano de publicação, referenciados por um identificador único.

Pesquisas na área da LP e tecnologia são realizadas já há algum tempo, no entanto, conforme mostra o mapeamento, a primeira publicação encontrada nas fontes pesquisadas, a abordar os dois temas (LP com m-learning), data de 2009 [1], mostrando que este é um tema recente. Em 2010 não foi encontrada nenhuma publicação nas fontes pesquisadas e em 2011 apenas uma publicação [2]. O panorama começa a mudar em 2012 com quatro publicações [3, 4, 5 e 6], seguido por uma em 2013 [7] e duas em 2014 [8 e 9], deixando claro que as pesquisas nesta área estão em ascensão. Das nove publicações selecionadas, cinco delas foram apresentadas no SBIE [1, 3, 4, 6 e 8] o que reforça a importância deste evento no cenário nacional e internacional, como pode ser visto na publicação [1] que contou a com participação da Universidade de Coimbra. publicações.

$\mathrm{Na}$ Tabela 6, é apresentada uma relação dos tópicos da LP abordados nas

Tabela 5: Tópicos da LP abordados por publicação

\begin{tabular}{|c|l|}
\hline id & \multicolumn{1}{|c|}{ Tópicos Abordados } \\
\hline 1 & Formação de palavras gerando cada letra do alfabeto \\
\hline 2 & $\begin{array}{l}\text { Adequação da Linguagem; Precisão vocabular; Construção frasal; Concisão; Correção gramatical: } \\
\text { concordância verbal e nominal; Regência, crase, pronomes ortografia; Pontuação: a vírgula; Pontuação: do } \\
\text { ponto aos parênteses; Concordância verbal; Concordância nominal; Flexões nominais; Flexões verbais; } \\
\text { Regência; Crase; Pronomes pessoais e colocação dos pronomes átonos; Pronomes demonstrativos e } \\
\text { relativos; Ortografia uso das letras; Acentuação gráfica; Uso do hífen. }\end{array}$ \\
\hline 3 & Alfabetização com letras, imagens e palavras \\
\hline 4 & As mudanças impostas pelo novo acordo ortográfico como acentuação e hífen \\
\hline 5 & Capacidade de síntese através de resumos \\
\hline 6 & Produção de texto \\
\hline 7 & $\begin{array}{l}\text { Não aborda um tema específico. O centro da discussão é em como o material é preparado e como os } \\
\text { recursos dos dispositivos móveis são aproveitados }\end{array}$ \\
\hline 8 & Acentuação e hífen \\
\hline 9 & Discute a criação de materiais com textos, imagens, infográficos e vídeos \\
\hline
\end{tabular}

É importante notar que, em geral, as propostas são para um tema específico, o que é uma característica particular das plataformas móveis. No entanto, a publicação [2] traz em sua abordagem uma grande cobertura da LP. Vale ressaltar que nesta publicação os autores não deixam claro como os dispositivos móveis foram utilizados, e um dos 
CBIE-LACLO 2015

Anais do XXVI Simpósio Brasileiro de Informática na Educação (SBIE 2015)

Tabela 6: Publicações selecionadas para este trabalho

\begin{tabular}{|c|c|c|c|c|c|c|c|}
\hline id & Título & Autor(es) & Proposta & Fonte & $\mathrm{Cl}$ & Instituição & Ano \\
\hline 1 & $\begin{array}{l}\text { Uma aplicação para o } \\
\text { ensino da língua portuguesa } \\
\text { para surdos utilizando o } \\
\text { SensorLibras }\end{array}$ & $\begin{array}{l}\text { João E. da R. Tavares, } \\
\text { Valderi Leithardt, Cláudio F. } \\
\text { R. Geyer, Jorge S. Silva }\end{array}$ & $\begin{array}{l}\text { Apresenta um par de luvas com sensores que detecta os movimentos } \\
\text { feitos por um surdo, envia os dados dos sensores a um host, que os } \\
\text { processa e os decodifica em letras da língua portuguesa. }\end{array}$ & SBIE & $\mathrm{Cl} 2$ & $\begin{array}{l}\text { FACENSA, } \\
\text { GPPD e } \\
\text { Universidade } \\
\text { de } \\
\text { Coimbra }\end{array}$ & 2009 \\
\hline 2 & $\begin{array}{l}\text { Programa de Nivelamento } \\
\text { de Matemática e Português: } \\
\text { M-learning com Vídeoaulas }\end{array}$ & 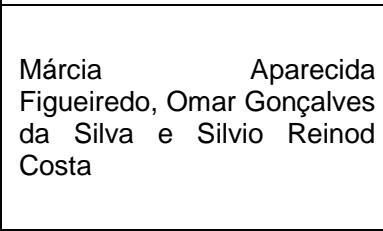 & $\begin{array}{l}\text { Apresentam o experimento realizado por } 3 \text { meses, com } 37 \text { turmas de } \\
\text { universitários calouros nas disciplinas de matemática e português, com a } \\
\text { finalidade de suprir deficiências deixadas pelo ensino médio, fazendo } \\
\text { uso de um AVA e dispositivos móveis. }\end{array}$ & $\begin{array}{c}17^{\circ} \\
\text { Congresso } \\
\text { Internacional } \\
\text { de } \\
\text { Educação a } \\
\text { Distância } \\
\text { (ABED) }\end{array}$ & $\mathrm{Cl} 3$ & $\begin{array}{l}\text { Centro } \\
\text { Universitário } \\
\text { Barão de } \\
\text { Mauá }\end{array}$ & 2011 \\
\hline 3 & $\begin{array}{l}\text { AlfabetoKinect: Um } \\
\text { aplicativo para auxiliar na } \\
\text { alfabetização de crianças } \\
\text { com o uso do Kinect }\end{array}$ & $\begin{array}{l}\text { Rodrigo de Sales Alves, } \\
\text { Jefferson Oliveira Alves de } \\
\text { Araujo, Francisco Madeiro }\end{array}$ & $\begin{array}{l}\text { Faz uso do mapeamento corporal do Kinect para desenvolver uma } \\
\text { interface que possibilita a interação natural e o aprendizado do alfabeto } \\
\text { por meio do reconhecimento verbal e de gestos. }\end{array}$ & SBIE & $\mathrm{Cl} 2$ & UNICAP & \multirow{4}{*}{2012} \\
\hline 4 & $\begin{array}{l}\text { OrtograFixe - Um jogo para } \\
\text { apoiar } \quad \text { o ensino- } \\
\text { aprendizagem das regras da } \\
\text { nova reforma ortográfica }\end{array}$ & $\begin{array}{l}\text { Diego Lopes Marques, Ana } \\
\text { Paula Serafim da Silva }\end{array}$ & $\begin{array}{l}\text { Apresenta um jogo para tablets Android com a proposta de trabalhar } \\
\text { com o novo acordo ortográfico da Língua Portuguesa. }\end{array}$ & SBIE & $\mathrm{Cl} 2$ & UFPB & \\
\hline 5 & $\begin{array}{l}\text { O Uso do Celular Como } \\
\text { Recurso Pedagógico Nas } \\
\text { Aulas de Língua Portuguesa }\end{array}$ & $\begin{array}{l}\text { Regina Cláudia Pinheiro e } \\
\text { Marcia Linhares Rodrigues }\end{array}$ & $\begin{array}{l}\text { Os autores relatam o trabalho com uma turma do } 8^{\circ} \text { ano que consistiu } \\
\text { em produzir o resumo de um conto e enviá-lo a um colega através de } \\
\text { SMS, de tal forma que o remetente, que não leu o conto, pudesse } \\
\text { compreendê-lo. }\end{array}$ & $\begin{array}{c}\text { Revista } \\
\text { Philologus, } \\
\text { Ano } 18, N^{\circ} \\
52\end{array}$ & $\mathrm{Cl} 1$ & UECE/FA7 & \\
\hline 6 & $\begin{array}{l}\text { Uma Ferramenta para } \\
\text { Monitorar o Processo de } \\
\text { Escrita Colaborativa entre } \\
\text { Alunos em Sala de Aula }\end{array}$ & $\begin{array}{l}\text { Josmário Albuquerque, } \\
\text { Glauber Leite, Diego } \\
\text { Dermeval, Rafaele Oliveira, } \\
\text { Ig Ibert Bittencourt, Alan } \\
\text { Silva, Eduardo Calil, Cristina } \\
\text { Felipeto }\end{array}$ & $\begin{array}{l}\text { Apresenta um sistema para monitoramento da produção de texto num } \\
\text { tablet de tela capacitiva, em sala de aula. O tablet grava o áudio e a } \\
\text { produção do texto, uma câmera externa grava o ambiente. Estas } \\
\text { informações são enviadas a um servidor que faz a junção destas } \\
\text { informações. }\end{array}$ & SBIE & $\mathrm{Cl} 3$ & UFAL & \\
\hline 7 & $\begin{array}{lr}\text { Integração } & \text { dos } \\
\text { Smartphones no Ensino do } \\
\text { Português: } & \text { Experiência } \\
\text { Interativa Com } & \text { Estudantes } \\
\text { de } 2^{\circ} \text { Ciclo } & \end{array}$ & Maria Barbas \& Ana Carlão & $\begin{array}{l}\text { Os autores fazem um aprofundamento nas origens e importância do m- } \\
\text { learning, na aprendizagem de línguas suportadas por dispositivos } \\
\text { móveis e propõe um estudo de caso a ser desenvolvido nas turmas de } \\
5^{\circ} \text { e } 6^{\circ} \text { anos com o uso de imagens, vídeos, voz, SMS, e outros recursos } \\
\text { e aplicativos disponíveis nos smartphones. }\end{array}$ & $\begin{array}{l}\text { REVISTA da } \\
\text { UIIPS, № } 3 \text {, } \\
\quad \text { Vol. } 1\end{array}$ & $\mathrm{Cl} 1$ & $\begin{array}{l}\text { Instituto } \\
\text { Politécnico de } \\
\text { Santarém }\end{array}$ & 2013 \\
\hline 8 & $\begin{array}{l}\text { JOE: Jogo Ortográfico } \\
\text { Educacional }\end{array}$ & $\begin{array}{llr}\text { Luan } & \text { Paschoal, } & \text { Tiago } \\
\text { Bento, Tauan Velasco, } & \text { Velocair, } \\
\text { Carlos Otávio Schocair } & \text { Oafael Castaneda, Talita } \\
\text { Raliveira, } & \text { Eduardo } \\
\text { Ogasawara } & \end{array}$ & $\begin{array}{l}\text { Apresenta um aplicativo para a plataforma Android que explora o novo } \\
\text { acordo ortográfico, abordando acentuação e hífen. }\end{array}$ & SBIE & $\mathrm{Cl} 2$ & CEFET/RJ & \multirow[t]{2}{*}{2014} \\
\hline 9 & 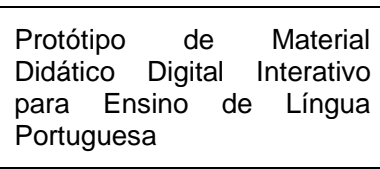 & Jezreel Gabriel Lopes & $\begin{array}{l}\text { Apresenta a proposta de material interativo para tablets fazendo uso do } \\
\text { aplicativo lbooks Author, que permite a criação de materiais pelo qual o } \\
\text { aluno possa navegar. }\end{array}$ & $\begin{array}{l}\text { EmRede } \\
\text { Revista de } \\
\text { Educação a } \\
\text { Distância v. } \\
\text { 1, n. } 1\end{array}$ & $\mathrm{Cl} 1$ & Unicamp/IEL & \\
\hline
\end{tabular}


principais recursos utilizados no trabalho foi um Ambiente Virtual de Aprendizagem (AVA), a fim de centralizar as informações, o que naturalmente permite uma maior cobertura dos assuntos.

$\mathrm{Na}$ Tabela 7, é apresentada a frequência com que cada tópico é abordado. Acentuação e hífen são os mais trabalhados, sendo objeto de estudo de três publicações [2, 4 e 8], que pode ser consequência do novo acordo ortográfico de 2009.

Tabela 7: Frequência com que os tópicos foram abordados

\begin{tabular}{|l|c|}
\hline \multicolumn{1}{|c|}{ Tópicos } & Frequência \\
\hline Acentuação e Hífen & 3 \\
\hline Formação de palavras, Capacidade de síntese e Ortografia & 2 \\
\hline $\begin{array}{l}\text { Alfabetização, Produção de texto, Precisão vocabular, Construção frasal, Correção gramatical, } \\
\text { Concordância verbal e nominal, Regência, Crase, Pronomes, Pontuação, Flexão verbal e nominal }\end{array}$ & 1 \\
\hline
\end{tabular}

Estes trabalhos cobrem muitos aspectos da LP do ponto de vista gramatical, visando tornar o aprendizado da língua mais dinâmico, e configuram-se como iniciativas com o intuito de levar a tecnologia que os alunos já utilizam no dia a dia para a sala de aula. Em contrapartida, os recursos dos dispositivos móveis foram pouco explorados: há pouca interação entre os alunos no meio virtual, e as propostas se limitam ao círculo individual. Os conceitos de gamificação foram pouco utilizados ou não foram utilizados, tornando o dispositivo móvel um simples substituto ao computador. Não foi encontrada em nenhuma das propostas, uma opção que permitisse ao aluno sanar alguma dúvida pontual, desde a escrita de alguma palavra específica, curiosidades sobre a língua - como, por exemplo, a origem das palavras -, e mesmo uma seção de dúvidas recorrentes como o emprego dos porquês, dentre outros.

Convém salientar que cada publicação tem sua contribuição para a área, por meio de seus resultados, o que já proporciona uma base mais sólida para trabalhos futuros, conforme é mostrado na Tabela 8 . As publicações omitidas [4, 7, 8 e 9] não apresentaram nenhum tipo de avaliação ou eram apenas de cunho teórico.

Tabela 8: Quanto aos testes realizados

\begin{tabular}{|c|c|c|c|}
\hline id & Tipo & Com quem? & Resultados \\
\hline 1 & Experimento & $\begin{array}{l}01 \text { surdo, } 20 \text { anos, } \\
\text { letrado em Libras e } \\
\text { Língua Portuguesa }\end{array}$ & $\begin{array}{l}\text { Validou-se a capacidade do dispositivo Sun SPOT como arquitetura para } \\
\text { leitura dos movimentos, através da boa qualidade na captura da } \\
\text { aceleração/ângulos de inclinação da mão. }\end{array}$ \\
\hline 2 & Experimento & $\begin{array}{c}37 \text { turmas universitárias } \\
\text { do } 1 \text { ํ período }\end{array}$ & $\begin{array}{l}\text { Segundo os próprios alunos, o material é ótimo e ajuda a fixar conceitos } \\
\text { esquecidos ou não aprendidos no ensino médio. }\end{array}$ \\
\hline 3 & $\begin{array}{l}\text { Pesquisa de } \\
\text { opinião }\end{array}$ & $\begin{array}{c}5 \text { educadores mestres e } \\
\text { doutores }\end{array}$ & $\begin{array}{l}\text { Concordaram que a proposta da aplicação estava clara; tem potencial } \\
\text { para cumprir a proposta, de ser utilizado em sala de aula, de ser utilizado } \\
\text { em casa sob orientação dos pais; e seu uso está intuitivo, no entanto, } \\
\text { melhorias devem ser realizadas para aprimoramento de reconhecimento } \\
\text { dos movimentos dos usuários, além de melhorias na interface gráfica, } \\
\text { assim como melhorias no nível de dificuldade de fases para o jogo. }\end{array}$ \\
\hline 5 & Experimento & 12 alunos do $8^{\circ}$ ano & $\begin{array}{l}\text { Segundo os autores, o trabalho obteve êxito, apenas um aluno produziu } \\
\text { um resumo que não permitia a compreensão do conto original. }\end{array}$ \\
\hline 6 & Experimento & $\begin{array}{l}\text { Uma dupla de alunos } \\
\text { entre } 5 \text { e } 8 \text { anos que já } \\
\text { se conheciam }\end{array}$ & $\begin{array}{l}\text { A partir da sincronização dos dados de escrita, audiovisuais e do } \\
\text { monitoramento completo do contexto que envolve a produção textual de } \\
\text { forma automatizada, é possível reavaliar as metodologias utilizadas no } \\
\text { processo de aprendizagem dos alunos em ambiente escolar. }\end{array}$ \\
\hline
\end{tabular}


Apesar de todas as publicações selecionadas fazerem uso ou citarem amplamente as tecnologias móveis, nem todas apresentam de fato algum aplicativo que pudesse ser obtido para testes, como é mostrado na Tabela 9.

Tabela 9: Aplicações propostas por publicação

\begin{tabular}{|c|c|c|}
\hline id & Propôs um Aplicativo? & Está Disponível? \\
\hline 1 & Sim (SensorLibras) & Não \\
\hline 3 & Sim (AlfabetoKinect) & Não \\
\hline 4 & Sim (OrtograFixe) & Sim \\
\hline 8 & Sim (JOE) & Sim \\
\hline
\end{tabular}

As publicações omitidas não propuseram uma aplicação, seu foco era na utilização de aplicações já existentes $[2,5,6]$ ou na proposta de materiais para tais dispositivos [7 e 9]. Por fim, é apresentado na Tabela 10 uma relação das tecnologias abordadas nas publicações selecionadas, e a frequência com que foram utilizadas.

Tabela 10: Tecnologias encontradas

\begin{tabular}{|l|c|}
\multicolumn{1}{|c|}{ Tecnologias } & Frequência \\
\hline Captura de movimentos com sensores & 2 \\
\hline $\begin{array}{l}\text { Kit Sun Spot, Tablet com tela capacitiva, Câmera IP com rede, Caneta para tela capacitiva, } \\
\text { Kinect, SMS, Chat, E-mail, AVA }\end{array}$ & 1 \\
\hline
\end{tabular}

Uma variedade de ferramentas e recursos diferentes foram utilizados, porém percebe-se uma carência em aplicações e propostas que explorem recursos dos dispositivos móveis como câmera, GPS, acelerômetro, Bluetooth, dentre outros. Estes recursos variam de acordo com o dispositivo, tornando sua utilização mais desafiadora, no entanto não há dúvida que sua utilização pode tornar a aplicação mais rica e atraente.

\section{Considerações Finais e Trabalhos Futuros}

Este mapeamento veio confirmar a ideia inicial da existência de poucas publicações relacionando a aprendizagem da LP com dispositivos móveis. Poucos trabalhos propõem um novo aplicativo, concomitantemente poucos exploram devidamente as possibilidades inerentes aos aparelhos móveis (em especial smartphones e tablets), especialmente seu grande potencial de inovação. Integrar estes dispositivos à educação significa também fazer uso dos mais diversos recursos que eles disponibilizam, tornando a aprendizagem mais interativa, prazerosa e imersiva na vida do aluno. Poucos serão os benefícios se os dispositivos móveis apenas substituírem os computadores na troca de arquivos, servindo apenas de suporte à leitura e vídeos.

Os trabalhos estudados mostraram bons resultados e boas propostas para a área, assim como boa receptividade por parte dos alunos, e principalmente mostrou que há ainda muito a se fazer para tornar o "m-learning" uma realidade mais presente nas escolas e na vida dos alunos.

Trabalhos futuros podem ser desenvolvidos em diversas áreas apontadas, utilizando princípios de gamificação, dado seu potencial para influenciar, engajar e motivar as pessoas [Borges et al. 2013], promovendo maior interação entre os próprios alunos, e o professor e a turma, através de atividades virtuais, e ainda possibilitando aos alunos consultas de dúvidas pontuais, podendo ser usado em sala como material de consulta. Outro ramo que também pode ser explorado é a proposta e desenvolvimento 
de materiais e atividades, que utilizem efetivamente os sensores dos dispositivos móveis, resultando numa interação maior com o usuário.

Estes resultados motivaram a proposta de um novo aplicativo (em fase de desenvolvimento) para a plataforma Android. A ideia é fazer a busca da origem das palavras da LP, uma vez que esta tem suas raízes em diversas línguas diferentes, podendo sanar dúvidas quanto à sua grafia, melhorar a interpretação do aluno acerca do sentido daquela palavra, e fornecer informações que complementem as regras gramaticais, e esta abordagem não foi feita por nenhum dos estudos apresentados. $\mathrm{O}$ processo de projeto e implementação deve ser relatado em uma publicação futura.

\section{Agradecimentos}

Os autores agradecem o apoio do "Programa de Qualificação em Grande Escala em Tecnologias Móveis - PROMOBILE", projeto patrocinado pela Samsung Eletrônica da Amazônia Ltda. nos termos da lei federal brasileira $n^{\circ}$ 8.248/91.

\section{Referências}

Albuquerque, J.; Leite, G.; Dermeval, D.; Oliveira, R.; Bittencourt I. I.; Silva, A.; Calil, E.; Felipeto, C. (2012) Uma Ferramenta para Monitorar o Processo de Escrita Colaborativa entre Alunos em Sala de Aula. Simpósio Brasileiro de Informática na Educação (SBIE). 2012.

Alves, G. M. T. e Aguiar, Y, P, C. (2014) Acessibilidade e Tecnologia Assistiva no Ambiente Educacional: Mapeamento Sistemático. Simpósio Brasileiro de Informática na Educação (SBIE). 2014.

Alves, R. S.; Araujo, J. O. A.; Madeiro, F. (2012) AlfabetoKinect: Um aplicativo para auxiliar na alfabetização de crianças com o uso do Kinect. Simpósio Brasileiro de Informática na Educação (SBIE). 2012.

Barbas, M. e Carlão, A. (2013) Integração dos Smartphones no Ensino do Português: Experiência Interativa com Estudantes de $2^{\circ}$ Ciclo. REVISTA da UIIPS - Unidade de Investigação do Instituto Politécnico de Santarém, № 3, Vol. 1, 2013.

Borges, S. S.; Reis, H. M.; Durelli, V. H. S.; Bitterncourt, I. I.; Jaques, P. A.; Isotani, S. (2013) Gamificação Aplicada à Educação: Um Mapeamento Sistemático. Simpósio Brasileiro de Informática na Educação (SBIE). 2013.

Figueiredo, M. A.; Silva, O. G.; Costa, S. R.(2011) "Programas de Nivelamento de Matemática e Português: M-Learning com Videoaulas", In: Congresso Internacional de Educação a Distância - ABED (Associação Brasileira de Educação a Distância), Manaus, 2011.

Kitchenham, B. A.; Budgen, D.; Pearl Brereton, O. (2011) "Using mapping studies as the basis for further research - A participant-observer case study", Information and Software Technology, Volume 53, Edição 6, Jun, 2011.

Kitchenham, B. A. e Charters, S., (2007) Guidelines for Performing Systematic Literature Reviews in Software Engineering. Technical Report EBSE-2007-01, 2007

Lopes, J. G. (2014) "Protótipo de Material Didático Interativo para Ensino de Língua Portuguesa", EmRede - Revista de Educação a Distância v.1, n.1, 2014. 
Luz, J. W. P; Fonseca, L. C. C. (2013) EduConnect: uma ferramenta de apoio à aprendizagem colaborativa para dispositivos móveis em redes MANET. Simpósio Brasileiro de Informática na Educação (SBIE). 2013.

Magalhães, C. V. C.; Santos, R. E. S.; Silva, F. Q. B.; Gomes, A. S. (2013) Caracterizando a Pesquisa em Informática na Educação no Brasil: Um Mapeamento Sistemático das Publicações do SBIE. Simpósio Brasileiro de Informática na Educação (SBIE). 2013.

Marques, D. L. e Silva, A. P. S. (2012) OrtograFixe - Um jogo para apoiar o ensinoaprendizagem das regras da nova reforma ortográfica. Simpósio Brasileiro de Informática na Educação (SBIE). 2012.

Meireles, E. S.; Correa, J. (2005). Regras Contextuais e Morfossintáticas na Aquisição da ortografia da Língua Portuguesa por Crianças. Em Psicologia: Teoria e Pesquisa. 2005. Vol, 21. n. 1. p. 77-84.

Meireles, E. S.; Correa, J. (2006). A relação da tarefa de erro intencional com o desempenho ortográfico da criança considerados os aspectos morfossintáticos e contextuais da língua portuguesa1. Em Estudos de Psicologia. 2006. 11(1). p. 35-43.

Nobili, G. G. e Barrera, S. D. (2009). Análise de erros ortográficos em alunos do ensino público fundamental que apresentam dificuldades na escrita. Em Psicologia em Revista. 2009. Vol. 15. n. 2. p. 36-55.

Paschoal, L.; Bento, T.; Velasco, T.; Schocair, C. O.; Castaneda, R.; Oliveira, T.; Ogasawara, E. (2014) .JOE: Jogo Ortográfico Educacional Simpósio Brasileiro de Informática na Educação (SBIE). 2014.

Petersen, K.; Feldt, R.; Mujtaba, S.; Mattsson, M. (2008) Systematic mapping studies in software engineering. In "Proceedings of the 12th international conference on Evaluation and Assessment in Software Engineering" (EASE'08), Giuseppe Visaggio, Maria Teresa Baldassarre, Steve Linkman, and Mark Turner (Eds.). British Computer Society, Swinton, UK, UK, 68-77, 2008.

Pinheiro, R. C. e Rodrigues, M. L. (2012) O Uso do Celular Como Recurso Pedagógico nas Aulas de Língua Portuguesa. Revista Philologus, Ano 18, N 52, 2012.

Ramires, L. O.; Souza, E. P. R.; Souza, J. N.; Freitas, M. R.; Janurio, M. V. S.; Silva, R. E. F.; Gomes, R. S. F.; Lima, T. A. B. (2013) Como a Tecnologia Assistiva tem auxiliado o Processo de Ensino/Aprendizagem? Mapeamento Sistemático a partir dos Trabalhos Publicados no SBIE. Simpósio Brasileiro de Informática na Educação (SBIE). 2013.

Sena, D. M; Oliveira, E. H. T; Carvalho, L. S. G. (2014) Aplicativos móveis para o aprendizado de matemática. Simpósio Brasileiro de Informática na Educação (SBIE). 2014.

Silva, A. R. S.; Façanha, A. R.; Viana, W.; Filho, J. A. C.; Sánchez, J. (2014) Especificação e desenvolvimento de um ambiente educativo móvel para a prática da escrita Braille. Simpósio Brasileiro de Informática na Educação (SBIE). 2014.

Tavares, J. E. R.; Leithardt, V.; Geyer, C. F. R.; Silva, J. S. (2014) Uma aplicação para o ensino da língua portuguesa para surdos utilizando o SensorLibras. Simpósio Brasileiro de Informática na Educação (SBIE). 2014. 